\title{
Comparison of TCP and TCP/HA Hybrid Scaffolds for Osteoconductive Activity
}

\author{
P. Wongwitwichot ${ }^{1}$, J. Kaewsrichan ${ }^{1, *}$, K.H. Chua ${ }^{2}$ and B.H.I. Ruszymah ${ }^{2}$ \\ ${ }^{I}$ Department of Pharmaceutical Chemistry, Faculty of Pharmaceutical Sciences, Prince of Songkla University, Hat-Yai, \\ Songkhla, Thailand \\ ${ }^{2}$ Department of Physiology, Faculty of Medicine, University Kebangsaan Malaysia, Jalan Raja Muda Abdul Aziz, 50300 \\ Kuala Lumpur, Malaysia
}

\begin{abstract}
Two types of porous ceramic scaffolds were prepared, consisting of $\beta$-tricalcium phosphate (TCP) or the mixed powder of TCP and hydroxyapatite (HA) at a 2:1 mass ratio. A variety of methods have been used to fabricate bone scaffolds, while the sintering approach was adopted in this work. An extremely high temperature was used on sintering that proposed to consolidate the ceramic particles. As revealed by SEM, a well opened pore structure was developed within the scaffolds. The $\theta$-values were measured to be of $73.3^{\circ}$ and $6.5^{\circ}$ for the composite scaffold and TCP sample, respectively. According to XRD patterns, the existence of grains coalescence and partial bonding between HA and TCP powders was demonstrated. Scaffold mechanical property in the term of flexural strength was also determined. The result showed decreasing of the strength by HA supplement, suggesting the more brittle characteristic of HA in comparison with TCP. By soaking the composite scaffold in PBS for a period of 2 weeks, transformation from particles to flank-like crystalline was clearly observed. Such change was found to be favorable for cell attachment, migration, and growth. By implanting cell-seeded scaffolds into nude mice, an abundant osseous extracellular matrix was identified for the composite implants. In contrast, the matrix was minimally detected in TCP implanted samples. Thus, the composite scaffold was found superior for hard tissue regeneration.
\end{abstract}

Keywords: Bone scaffold, hard tissue engineering, hydroxyapatite, $\beta$-tricalcium phosphate, osteoconductive.

\section{INTRODUCTION}

Bone is a remarkable organ playing critical functions in human physiology including protection, movement and support of other critical organs, blood production, mineral storage and homeostasis, blood $\mathrm{pH}$ regulation, multiple progenitor cells housing, and other [1]. The importance of bone becomes clear in the case of diseases such as osteoarthritis, osteomyelitis, and osteoporosis where bone does not function properly [2]. Along with traumatic injury, orthopedic surgery, and tumor resection, these lead to or induce bone defects or voids of which bone replacement is typically required. Autologous bone grafting is the gold standard in reconstructive surgery owing to high immunocompatibility. However, the concept is bound by several constraints relating to requirement of secondary surgery, limited amount of tissue that can be harvested, as well as increased risk of infection or recurrent pain [3]. To overcome these problems, tissue engineering approaches are emerging as convenient alternatives to promote the regenerative ability of the host body $[4,5]$.

One of the most important stages of bone tissue engineering is the design and processing of a porous, biodegradable 3D structure called a scaffold. The scaffolds should provide

*Address correspondence to this author at the Department of Pharmaceutical Chemistry, Faculty of Pharmaceutical Sciences, Prince of Songkla University, Hat-Yai, Songkhla, 90112, Thailand; Tel/Fax: +66 74 428239;

E-mail: jasadee.k@psu.ac.th structural support for cells and newly formed tissues by acting as a temporary extracellular matrix for natural processes of tissue regeneration and development. In the meantime, they should degrade at a rate comparable with new tissue growth [5]. Porosity is one of physical parameters for scaffolds necessary to be determined, since it provides adequate space for cell migration and expansion, and maintains the transport of nutrients and waste products [6,7]. In general, the interconnected pores of $100 \mu \mathrm{m}$ diameter are considered as a minimum requirement $[8,9]$. Therefore, the improvement of biological activity and performance of bonesubstitute materials and scaffolds is one of the major concerns in bone regeneration [10].

A variety of biomaterials have been shown to help repair or replace damaged bone tissue. Each has its strengths and weaknesses, and no one has been demonstrated to stand above the rest. Opportunities thus exist for the discovery of the best possible material to use [11]. Bioactive ceramics such as hydroxyapatite (HA), tricalcium phosphate (TCP), or the combination of them have drawn interest for hard tissue regeneration owing to their structural and chemical similarity with the inorganic component of bone [12]. These materials are osteoconductive because of exhibiting the capability to bond with bone and soft tissue, and stimulating bone growth [13]. HA demonstrates greater hydrophobic property, and possesses lower resorption rate than TCP. There have been advantageous in pairing HA with TCP, as some designed parameters such as degradability and surface characteristics of the engineered scaffold have been improved [14]. In addi- 
tion, mechanical strength and fracture toughness of HA is ameliorated when a secondary phase of low melting point bioceramic was added on sintering [15].

Two promising approaches generally applied in bone tissue engineering to address the challenging requirements listed above include cell and acellular transplantations [16]. In the first strategy, mesenchymal stem cells (MSCs) are isolated from the patient, expanded ex vivo, seeded onto a scaffold and allowed to produce extracellular matrix (ECM) on the scaffold in controlled culture conditions, and finally implanted into osseous defect or void in the patient. In the second approach, however, a scaffold without cells is implanted immediately after injury/bone removal. MSCs are pluripotent cells capable of differentiation into a number of cell types. Also, they can be driven towards bone forming cells or osteoblasts which produce ECM within the scaffold ex vivo. In many preclinical trials, transplantation of scaffolds seeded with MSCs has been shown to enhance osteogenic capacity by integrating with native tissue faster than acellular scaffolds [17]. Despite indicating significant potential in bone tissue engineering, a primary obstacle in translating the first technique from the bench to the bedside is that the patient must wait for the bone graft to develop in vitro. Therefore, the ex vivo culture is generally supplemented with suitable osteoinductive factors, intending to promote rapid development of a ready-transplant cellular scaffold [18].

In this work, scaffolds with newly designed-TCP based ceramics were developed. The impacts of HA on structural and surface properties, as well as on mechanical strength of the scaffolds were determined. Moreover, the osteoconductive capacity of the fabricated scaffolds was evaluated in vivo in nude mice.

\section{MATERIALS AND METHODS}

\section{Fabrication of TCP or HA/TCP Scaffolds}

HA and TCP powders with the respective mean particle sizes of 7.9 and $4.7 \mu \mathrm{m}$ were purchased from Sigma-Aldrich. The sieved sucrose particles $(400-600 \mu \mathrm{m}$ in diameter) were mixed with TCP or TCP plus HA using electric mixer. The procedure for fabricating scaffolds was schematically illustrated in Fig. (1). The mass ratio of inorganic substance(s) to sucrose was set constantly at 9:1. Two types of scaffolds were prepared: HT63 and T80. HT63 was consisted of HA, TCP and sucrose at a mass ratio of $6: 3: 1$, while T80 contained TCP and sucrose at 9:1 ratio by mass. Polyvinyl alcohol $(15 \% \mathrm{w} / \mathrm{v})$ was used as a binder in wet mixing. The mixture was casted into a glass mould, cut into an optimal size, and dried at $37^{\circ} \mathrm{C}$ for 3 days. The dried sample was pressed in a mould using hydraulic pressing apparatus. Scaffold samples were heated at $500{ }^{\circ} \mathrm{C}$ for $4 \mathrm{~h}$, and sintered at $1230{ }^{\circ} \mathrm{C}$ for $4 \mathrm{~h}$. The heating rate of $15{ }^{\circ} \mathrm{C}$ per minute was used in both steps.

\section{Physical Characterization of the Prepared Scaffolds}

Scanning Electron Microscope (SEM) (Quanta 400, FEI, Czech Republic) was used to characterize surface morphology, pore shape and size, and pore distribution of the fabricated scaffolds after gold coating.

Hydrophilic/hydrophobic property of the scaffold surfaces was determined by measuring the contact angle $(\theta$,

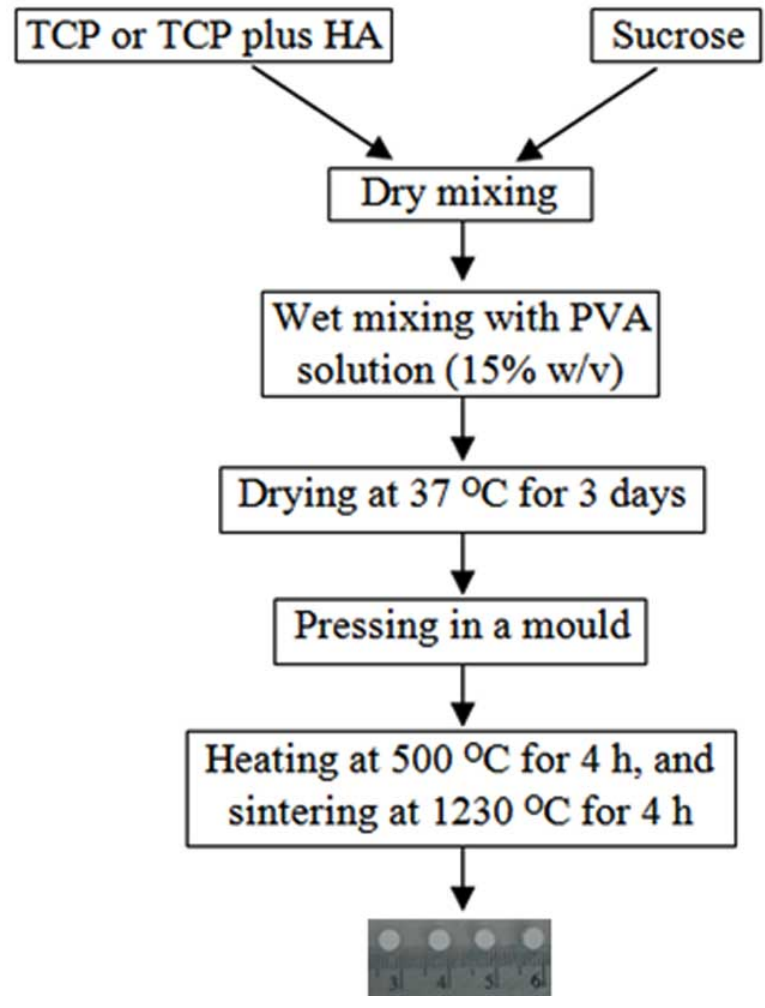

Fig. (1). Schematic demonstration of the procedure used to fabricate scaffolds.

OCA15+, Data-physics, Germany). The $\theta$ is the angle at which a liquid/vapor interface meets the solid surface. If the angle $\theta$ is less than $90^{\circ}$, the liquid is said to wet the solid. If it is greater than $90^{\circ}$, it is said to be non-wetting. A zero contact angle represents complete wetting. If the liquid is water, the lesser $\theta$ means more hydrophilic of the solid surface.

Crystal structure and phase composition of scaffold samples were detected using X-ray diffractometer. It was operated with $\mathrm{Cu} \mathrm{K} \alpha$ radiation $(\lambda=0.154 \mathrm{~nm})$ (X'Pert Pro MPD, Philips, The Netherlands), scanning in a continuous mode from $30^{\circ}-80^{\circ}$ with a scanning rate of $2 \% \mathrm{~min}$.

The flexural strength of the resulting products $(25 \mathrm{~mm} x$ $60 \mathrm{~mm} \times 9 \mathrm{~mm}$ in dimensions) was determined by using LLOYD Compressive Tester equipped with a $100 \mathrm{~N}$ load cell. The cross-head speed was set at $10 \mathrm{~mm} / \mathrm{min}$. The strength was calculated from the maximum load recorded. Three samples were tested for each condition. Data were analyzed statistically using Student $t$ test and significance was considered at $p<0.05$.

\section{Soaking the Scaffolds in Phosphate Buffer Saline (PBS) pH 7.4}

The PBS solution was prepared by dissolving $80 \mathrm{~g} \mathrm{NaCl}$, $2 \mathrm{~g} \mathrm{KCl}, 14.4 \mathrm{~g} \mathrm{Na}_{2} \mathrm{HPO}_{4}$ and $2.4 \mathrm{~g} \mathrm{KH}_{2} \mathrm{PO}_{4}$ in a liter of water, and adjusted to $\mathrm{pH} 7.4$ [19]. Triplicate samples from each group of the scaffolds were immersed in $20 \mathrm{ml}$ of PBS for 2 weeks at $37{ }^{\circ} \mathrm{C}$ without stirring. After removal, the sample was gently washed with deionized water, and dried at room temperature. The corresponding non-immersed scaffold was served as the control. SEM was performed to examine surface characteristics of the scaffolds before and after soaking. 


\section{Preparation of Marrow Stromal Cells for Seeding on Scaffolds}

\section{Culturing of Bone Stem Cells}

Bone marrow cells of human origin were kindly obtained from Dr. Leong Chooi Fun (Department of Physiology, Faculty of Medicine, Universiti Kebangsaan Malaysia, Kuala Lumpur). Ficoll-plaque ${ }^{\mathrm{TM}}$ PLUS (Amersham Biosciences) was used in isolation of primary mesenchymal cells $\left(\mathrm{P}_{0}\right)$ from the whole marrow cells. The undifferentiated $\mathrm{P}_{0}$ line was cultured on a $25 \mathrm{~cm}^{2}$-flask $\left(\mathrm{Nunc}^{\circledR}\right)$ using Dulbecco's modified Eagle medium-F12 (DMEM-F12) supplemented with $10 \%$ fetal bovine serum (FBS), and $1 \%$ penicillin/streptomycin/amphotericin B at $37{ }^{\circ} \mathrm{C}$ in $5 \%$ carbon dioxide. The medium was changed every 2-3 days. All of the culture media and chemicals were purchased from Gibco.

\section{Differentiation of $P_{0}$ into Preosteoblasts}

The osteogenic induction conditions used in this study were in according to our previously described method [18]. Briefly, the $\mathrm{P}_{0}$ cells $(60 \%$ confluence) were starved in basal medium (DMEM-F12 plus $1 \%$ FBS, and $1 \%$ penicillin/streptomycin/amphotericin B) for $12 \mathrm{~h}$ at $37{ }^{\circ} \mathrm{C}$ in $5 \%$ carbon dioxide. The medium was changed to serum free medium (SFM) on the day of induction. The cells were then challenged by $2.5 \mathrm{ng} / \mathrm{ml}$ FGF2 (Merck Biosciences, Germany) for $24 \mathrm{~h}$, and left in basal medium for next 2 days. This was followed by changing the culture medium to SFM, and the addition of $10 \mathrm{ng} / \mathrm{ml}$ BMP2 (BioVision, USA). The cells were cultured in the presence of BMP2 for another $24 \mathrm{~h}$ before harvesting.

\section{Seeding of Preosteoblasts onto Scaffolds}

At the end of the induction period, the cell monolayer was washed twice with PBS. The differentiated cells were scraped from the cultured flask, and dispersed in a small volume of PBS. The scaffolds were submerged in $70 \%$ ethanol for $12 \mathrm{~h}$ for sterilization, and soaked several times in PBS to remove ethanol. The sterilized scaffolds were placed on tissue culture plates $(6-\mathrm{cm}$ diameter), and seeded with a $100-\mu 1$ cell suspension containing approximately of $10^{7}$ differentiated cells. The seeded scaffolds were incubated at $37{ }^{\circ} \mathrm{C}$ in $5 \% \mathrm{CO}_{2}$ for $1 \mathrm{~h}$ to allow cell attachment.

\section{Implantation of the Seeded Scaffolds in Nude Mice}

Two-month-old nude mice (MF1) were kept in controlled environment, cared for and treated regarding to the institutional guidelines (The ethic approval no. FF-253-2009, Faculty of Medicine, Universiti Kebangsaan Malaysia). The animals were anesthetized intramuscularly by the mixture of Xylazine $(25 \mathrm{mg} / \mathrm{ml})$, Ketamine $(25 \mathrm{mg} / \mathrm{ml})$, and Zoletil $(12.5 \mathrm{mg} / \mathrm{ml})$ at $1: 1: 1$ volume ratio with a $100-\mu l$ volume per $25 \mathrm{~g}$ body weight. The seeded scaffolds were implanted on the back of the mice. The experiment was performed on triplicate mice, each carrying the duplicate of three sample types: HT63, T80 and BD (Fig. 2). Control scaffolds, called $\mathrm{BD}$, were purchased from BD Bioscience in a sterilized form of rigid, preformed calcium phosphate. They were manipulated using similar manners as described for the tested scaffolds. The animals were killed 4 weeks after implantation. The grafts were then removed and processed for histological analysis.

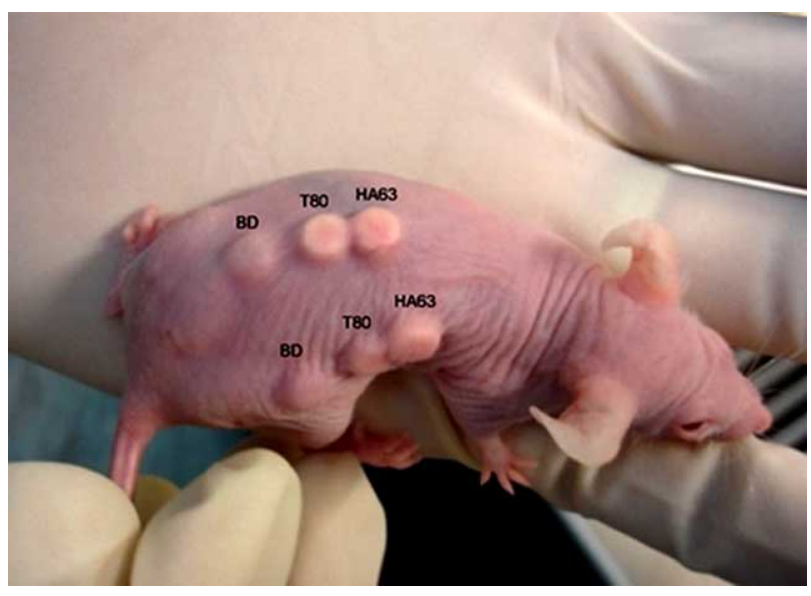

Fig. (2). Implantation of the seeded scaffolds on the back of nude mice. There were triplicate mice taken in the surgical experiment. Each carrying the duplicate of three scaffold types: HT63, T80 and $\mathrm{BD}$ (the control).

\section{Histological Analysis}

The implanted grafts were fixed overnight in $10 \%$ formaldehyde in PBS and decalcified for 3-4 h in $8 \% \mathrm{HCl}$ saturated with EDTA. The resulting grafts were paraffin embedded, sectioned (5- $\mu \mathrm{m}$ thickness), and stained with hematoxylin-eosin (HE) or alizarin red S. For each sample, at least two different section levels and two histological sections for each level were analyzed.

\section{RESULTS}

\section{Morphology of the Tested Scaffolds}

SEM images of the prepared scaffolds and the commercial product were demonstrated in Fig. (3). An opened pore structure was developed in both types of the fabricated scaffolds (3A and $3 \mathrm{~B})$. A denser microstructure with smaller pore size $(15 \pm 3 \mu \mathrm{m})$ was revealed by HT63 composites, whereas larger pores of $43 \pm 8 \mu \mathrm{m}$ diameter were formed in T80 scaffolds. According to "The product manual" of BD Bioscience, the pore diameter of BD scaffolds ranged between 200 and $400 \mu \mathrm{m}$ (Fig. 3C). A homogeneous phase inside the composite scaffolds (HT63) was observed, but grain boundary was generally apparent in TCP samples (T80). Thus, the pore structure was changed by adding HA into TCP scaffold base. The removal of polyvinyl alcohol at high temperatures provided interconnected porous structure with porosity of approximately $40 \%$, as demonstrated in Fig. (3A and 3B).

\section{Contact Angle ( $\theta)$}

Surface hydrophilic/hydrophobic property was determined by using water contact angle $(\theta)$. Results revealed that the $\theta$-values of HT63 and T80 samples were of $73.3^{\circ} \pm 2.9^{\circ}$ and $6.5^{\circ} \pm 0.3^{\circ}$, respectively. Increased surface hydrophobicity was obtained by the addition of HA into TCP base in which the consequence was dependent on the amounts of HA added (results not shown).

\section{XRD Analysis}

The XRD patterns of TCP powders and the compounded HA/TCP (at 2:1 ratio by mass) were represented in Fig. (4). 

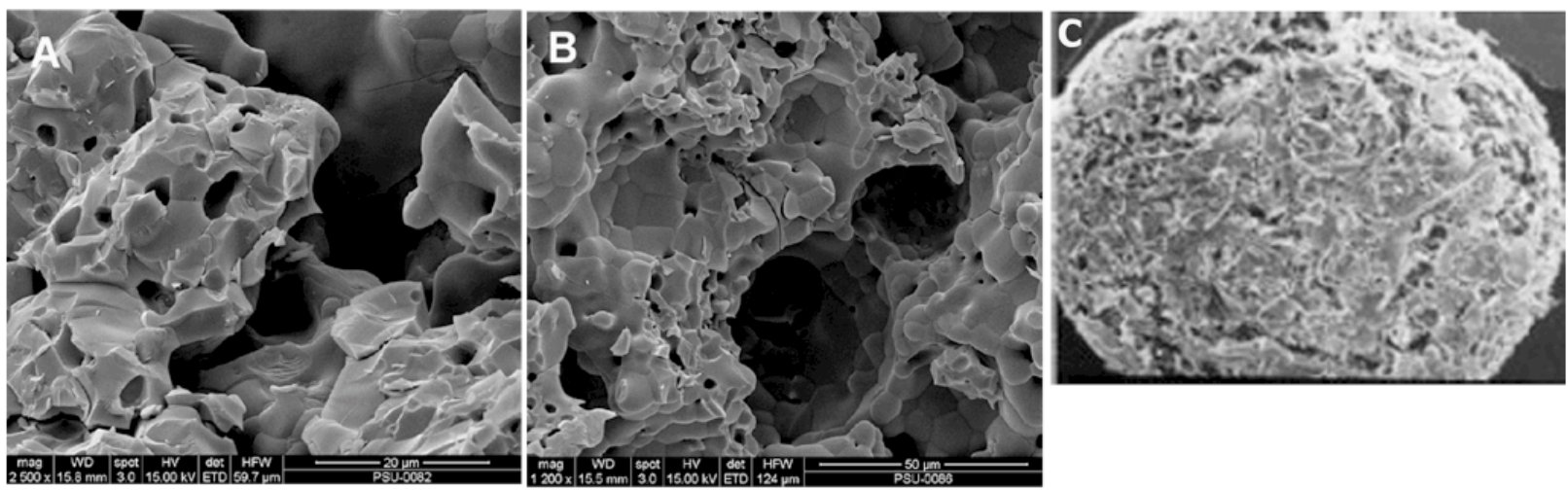

Fig. (3). SEM images of the fabricated scaffolds (A and B) and the commercial product from BD Bioscience (C). A: HT63, composed the combination of HA and TCP at a 2:1 mass ratio; B: T80, prepared by using pure TCP; $\mathrm{C}$ : the scaffold called BD, being the calcium phosphate based structure obtained from BD Bioscience.

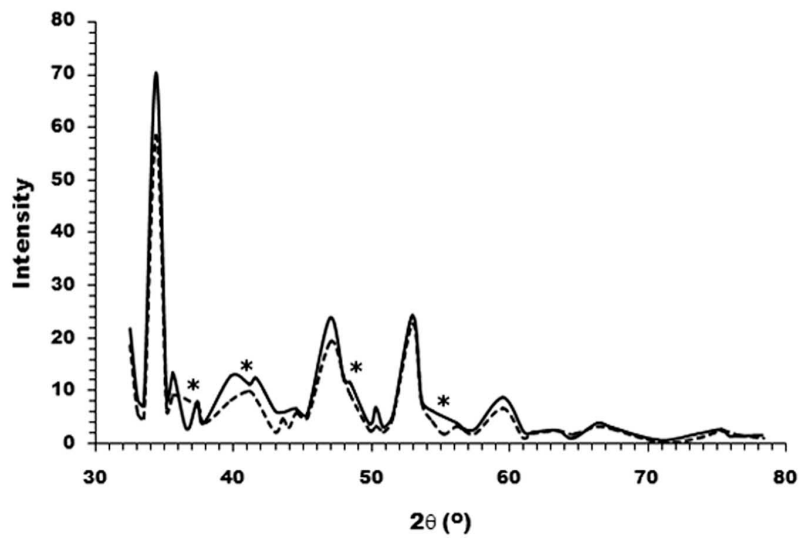

Fig. (4). XRD patterns of TCP powder (-) and the mixture of HA and TCP at a mass ratio of 2:1 (---). Several separated peaks were observed for TCP sample, whereas a few merged peaks were apparent for the composite as marked by asterisks.

It was obvious to see a few merged peaks of the HA/TCP hybrid, which was in contrast to the separated peaks of TCP sample. The result indicated an occurrence of new composite upon prolonged heating the mixed ceramics at extremely high temperature.

\section{The Flexural Strength}

The mechanical property of the scaffolds was measured in the term of flexural strength. The strength was calculated to be of $64.5 \pm 1.8 \mathrm{MPa}$ for T80 samples, and of $25 \pm 1.2 \mathrm{MPa}$ for HT63 scaffolds. Thus, decreasing of the strength was responsible to $\mathrm{HA}$ addition, and was estimated to be due to the more brittle property and the higher melting point of HA.

\section{Soaking the Scaffolds in PBS}

The responses of HT63 composite and T80 scaffold in contact with PBS pH 7.4 were analyzed using SEM. SEM micrographs of the scaffolds before and after submerging in PBS at $37{ }^{\circ} \mathrm{C}$ for a period of 2 weeks were depicted in Fig. (5). Before soaking, the surfaces of both scaffold types were fully covered with the ceramic particles (Fig. 5A). After soaking, a huge change in surface morphology was evident for the composite scaffold, as plentiful apatite-like deposits were observed on its surface (Fig. 5B). This result was in contrast to that revealed by T80 samples in that a sole increasing of porosity within the scaffold structure was demonstrated (Fig. 5C).

\section{Histological Observations}

The pre-induced MSCs (see Materials and Methods) were seeded onto the tested scaffolds: HT63, T80, and the control BD. Then, cell-loaded scaffolds were implanted on the back of nude mice. The implants were processed for histological analysis 4 weeks later. Results indicated that a number of cells infiltrated into BD scaffolds (Fig. 6A). However, the scaffold matrices were vastly filled with fibrous tissue instead of newly formed bone tissue (Fig. 6D).
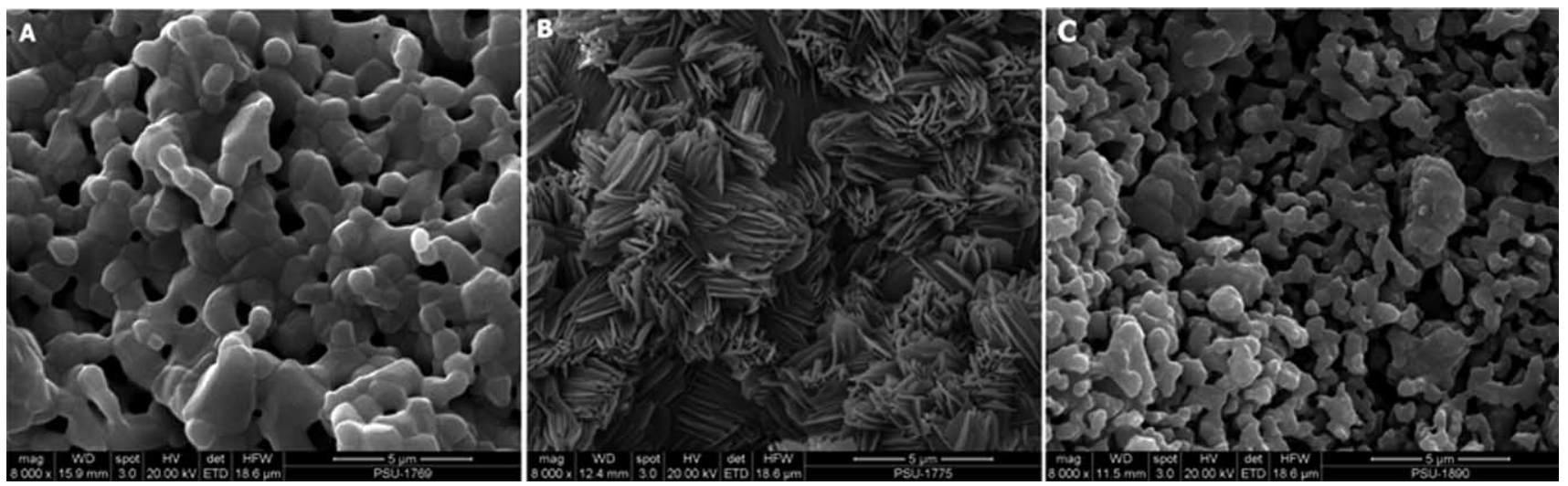

Fig. (5). SEM micrographs of HT63 composite before (A) and after (B) immerged in PBS pH 7.4 at $37{ }^{\circ} \mathrm{C}$ for 2 weeks. The image of T80 scaffold before soaking was similar to that revealed by the composite scaffold (A), thus was not shown here. The internal structure/ morphology of the submerged T80 showed increasing of porosity (C). 

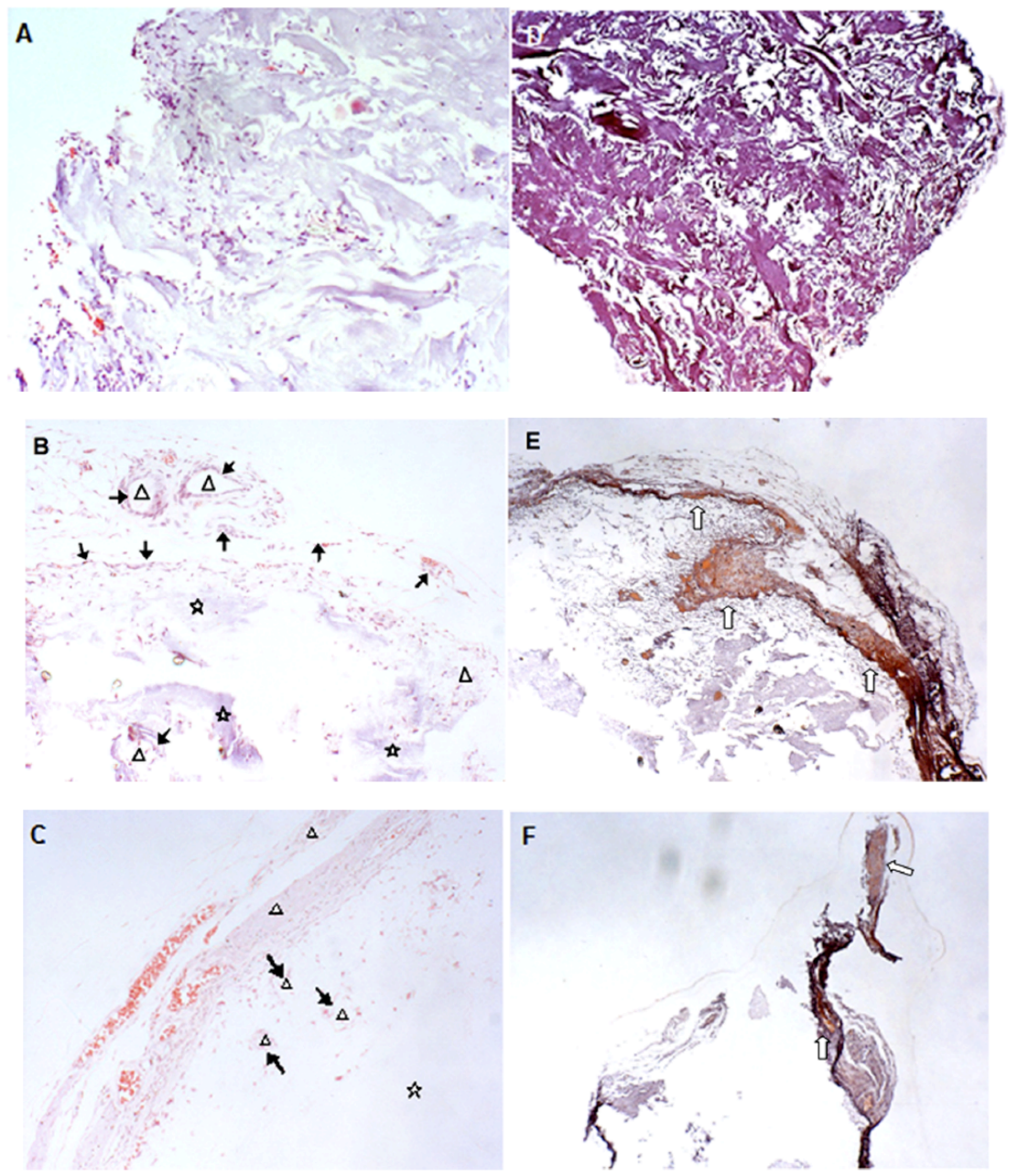

Fig. (6). Photomicrographs of the implanted sections at magnification $x 100$ for HE staining (A-C), and x40 for alizarin red S staining (D-F). The MSCs were sequentially induced with $2.5 \mathrm{ng} / \mathrm{ml} \mathrm{FGF2}$ and $10 \mathrm{ng} / \mathrm{ml} \mathrm{BMP} 2$ (see Materials and Methods). The differentiated cells were ectopically implanted in nude mice following adsorbed on the tested scaffolds: BD (A and D); HT63 (B and E); and T80 (C and F). Symbols: $\triangle$, newly formed bone tissue; $\mathbf{4}$, osteoblasts lining around new bone formed; $\boldsymbol{i} \boldsymbol{t}$, the remaining scaffold material; $\hat{\sim}$, new mineralized tissues.

Interestingly, clusters of new bone tissue were observed for HT63 implants. The clusters were surrounded by a numbers of osteoblasts, indicating active bone formation inside the scaffolds (Fig. 6B). An abundant osseous extracellular matrix was identified by alizarin red S staining (Fig. 6E). In the contrary, little regenerated bone cells were found in T80 implanted samples (Fig. 6C). The matrix was insignificantly detected, mostly around the outermost region (Fig. 6F). As indicated in Fig. (6B and 6C), parts of scaffold materials remained to be un-degradable within a period of 4 weeks of implantation.

\section{DISCUSSION}

This study was carried out to fabricate a bone scaffold with high mechanical strength and excellent biocompatibility. The porous HA has attached mush attention as bone substitutes because of its ability to lead osteoconduction. However, one of the main drawbacks for real applications is its poor mechanical property. To overcome this problem, the combination of HA and a secondary phase bioceramic with lower melting point such as TCP was derived.

Among many fabrication methods, the sintering approach was adopted in this work in which an extremely high tem- perature $\left(1230{ }^{\circ} \mathrm{C}\right)$ was used to consolidate HA particles. The method was found to be quite effective in obtaining highly porous structure. In addition, the minimal degradation of HA and the maximum level of strength of the resulting scaffolds was compromised. In fact, the sinter-ability of inorganic powders is strictly related to the starting morphology and chemical composition. The presence of volatile moieties, as water and carbonate, is an obstacle to powder densification and can provoke cracks and bubbles [20]. Therefore, prolonged heating at a low temperature of $500{ }^{\circ} \mathrm{C}$ was effective in yielding the resistant bioceramics. The composite of HA/TCP also exhibited high mechanical strength, consisting with the result of previous study [21]. At the temperature of sintering, the grains of HA and TCP were coalesced, obtaining a homogeneous composite as characterized by SEM (Fig. 3A). The interconnected pores within scaffold structures were introduced, as sucrose and the binder were removed upon heat treatment. By using 10\% w/w sucrose, the porosity of about $40 \%$ was measurable (Fig. 3A and 3B). It was possible to change the porosity, just by increasing the sugar content on the preparation of dry mixtures. However, the products' mechanical strength was decreased, accountable for increasing the porosity (results not shown), and be beyond the strength limit of hard tissue applications. 
A denser microstructure with smaller pore size $(15 \pm 3$ $\mu \mathrm{m}$ ) was revealed by HA/TCP composites (Fig. 3A). In contrast, the microstructure of TCP scaffolds was more loosened with wider pore diameter of $43 \pm 8 \mu \mathrm{m}$ (Fig. 3B). The results suggested coalescing of the ceramic grains, as decreased residual porosity was taken place [20]. In compared to HA, the mechanical strength of the scaffolds consisting of HA and TCP was improved, while the property was deteriorated regarding to pure TCP (results not shown). This was due to the more brittle characteristic of the former bioceramic. By the current formulation and processing, mechanical problems usually encountered for load bearing applications was overcome. In addition, the porous and opened pore structures were assumed to be used in segmental bone defects [22]. Surface hydrophilicity was clearly affected by HA i.e., the decreasing was proportional to the amounts of HA supplemented in the combination (data not shown). The resulting hybrid scaffold demonstrated suitable physical and mechanical properties, drawing interest towards the in vivo investigation for its competency.

The ability of particular materials to serve as a scaffold on which bone cells can attach, proliferate, and be mineralized is called osteoconduction [5]. The prepared scaffolds were tested for such the property in nude mice in comparison with the controls, BD. Before seeding onto the scaffolds, human MSCs were prior induced with a growth stimulation factor, FGF2, and subsequently with a differentiation factor, BMP2 [18]. The seeded scaffolds were then ectopically implanted on the back of nude mice for which histological analysis was performed 4 weeks later. By aiming to evaluate early histological changes, the relatively short time period was limited for this work. There were no phagocytes observed in the tissue sections (Fig. 6A-C), suggesting that bacterial infection and tissue inflammation did not take place, and that the implanted materials were biocompatible [22]. For HA/TCP implants, they were filled with a wellestablished layer of bony tissue (Fig. 6B) with abundant osseous extracellular matrices (Fig. 6E). However, little new bone was detected for TCP implants (Fig. 6C and 6F). Indeed, the extracellular matrices of the control scaffolds were mostly filled with fibrous tissue (Fig. 6A and C). Thus, the osteoconductive activity was significantly distinct among the tested scaffolds in which the highest activity was revealed by the composite bioceramics. The appropriate microenvironmental conditions seemed to be established on the surfaces of HA/TCP scaffold in vivo [23]. Fig. (5B) demonstrated the formation of apatite-like crystals on HA/TCP surfaces after soaking in PBS for 2 weeks (Fig. 5B), whereas that of TCP samples was not visualized (Fig. 5C). This was supposed to associate with the partial dissolution of calcium phosphate crystals by which the super-saturation of calcium and phosphate ions in the microenvironment was generated. Then, the precipitation of carbonate hydroxyapatite was emerged by incorporating carbonate and magnesium ions present in the biological fluid into actions [24]. In accorded with the previous studies [25-27], transformation from particles to flank-like crystalline in situ was more apparent for HA biomaterial. This change was favorable for cell attachment, migration, and growth, and greatly affected the bioactive characteristics of HA/TCP composite. Moreover, the porosity of porous TCP structures was increased after soaking (Fig. 5C). This increment was estimated to exist in situ, influencing cell migration. As a result, by using the prepared scaffolds, newly formed bone tissues were detected at inner parts of the implants. Since pore diameters of the prepared scaffolds were lower than the requirement limit of $100 \mu \mathrm{m}$, it was possible to exclude them from testing trials early. Interestingly, the results suggested that limited pore size was not be a major obstacle affecting osteoconductive activity of the engineered scaffolds. In helping with the selected osteoinductive factors, FGF2 and BMP2, the porous HA/TCP composite scaffolds played important roles in facilitating cell attachment and the retention of infiltrated cells, as well as promoting them to form new bone. Consequently, it would be applied for general use in hard tissue regeneration.

\section{ACKNOWLEDGEMENT}

We thank Center of Excellence on Nanotechnology at PSU, Drug Delivery Excellence Center at Faculty of Pharmaceutical Sciences, and the Prince of Songkla University for financial support of this work.

\section{REFERENCES}

[1] R. Langer, and J.P. Vacanti, "Tissue engineering”, Science, vol. 260, pp. 920-926, 1993.

[2] J.R. Porter, T.T. Ruckh, and K.C. Popat, "Bone tissue engineering: A review in bone biomimetics and drug delivery strategies", Biotechnol. Prog., vol. 25, pp. 1539-1560, 2009.

[3] O. Arosarena, "Tissue engineering", Curr. Opin. Otolaryngol. Head Neck Surg., vol. 13, pp. 233-241, 2004.

[4] J.M. Kanczler, and R.O. Oreffo, "Osteogenesis and angiogenesis: the potential for engineering bone", Eur. Cell Mater., vol. 15, pp. 100-114, 2008.

[5] S.H. Lee, and H. Shin, "Matrices and scaffolds for delivery of bioactive molecules in bone and cartilage tissue engineering", $A d v$. Drug Deliv. Rev., vol. 59, pp. 339-359, 2007.

[6] B.E. Chaignaud, R. Langer, and J.P. Vacanti, "The history of tissue engineering using synthetic biodegradable polymer scaffolds and cells," in Synthetic Biodegradable Polymer Scaffolds, A. Atala, and D.J. Mooney, Eds. MA: Birkhauser, 1997, pp. 1-14.

[7] R.C. Thompson, M.C. Wake, M.J. Yasemski, and A.G. Mikos, "Biodegradable polymer scaffolds to regenerate organs", Adv. Polym. Sci., vol. 122, pp. 245-274, 1995.

[8] Y.H. Hu, D.W. Grainger, S.R. Winn, and J.O. Hollinger, "Fabrication of poly ( $\alpha$-hydroxy acid) foam scaffolds using multiple solvent systems", J. Biomed. Mater. Res., vol. 59, pp. 563-572, 2002.

[9] C.J. Liao, C.F. Chen, J.H. Chen, S.F. Chiang, Y.J. Lin, and K.Y Change, "Fabrication of porous biodegradable polymer scaffolds using a solvent merging/particulate leaching method", J. Biomed. Mater. Res., vol. 59, pp. 676-681, 2002.

[10] N. Le Bolay, V. Santran, G. Dechambre, C. Combes, C. Drouet, A. Lamure, and C. Rey, "Production by co-grinding in a media mill, of porous biodegradable polylactic acid apatite composite materials for bone tissue engineering", Powder Techol., vol. 190, pp. 89-94, 2009.

[11] Y. Kimura, "Biodegradable polymers in Biomedical Applications," in Polymeric Materials, T. Tsuruta, Ed. Boca Raton: CRC Press, 1993, pp.163-190.

[12] J.C. Knowles, "Phosphate based glasses for biomedical applications", J. Mater. Chem., vol. 10, pp. 2395-2410, 2003.

[13] L.L. Hench, and J.M. Polak, "Third-generation biomedical materials", Science, vol. 295, pp. 1014-1017, 2002.

[14] S.H. Kwon, Y.K. Jun, S.H. Hong, I.S. Lee, and H.F. Kim, "Calcium phosphate bioceramics with various porosities and dissolution rate", J. Am. Ceram. Soc., vol. 85, pp. 3129-3131, 2002.

[15] K.A. Hing, S.M. Best, and W. Bonfield, "Characterization of porous hydroxyapatite”, J. Matter. Med., vol 10, pp. 135-145, 1999.

[16] D. Logeart-Avramoglou, F. Anagnostou, R. Bizios, and H. Petite, "Engineering bone: challenges and obstacles", J. Cell Mol. Med., vol. 9, pp. 72-84, 2005.

[17] J.R. Mauney, V. Volloch, and D.L. Kaplan, "Role of adult mesenchymal stem cells in bone tissue engineering applications: current status and future prospects", Tissue Eng., vol 11, pp. 787-802, 2005 . 
[18] J. Kaewsrichan, P. Wongwitwichot, K. Chandarajoti, K.H. Chua, and B.H.I. Ruszymah, "Sequential induction of marrow stromal cells by FGF2 and BMP2 improves their growth and differentiation potential in vivo", Arch. Oral Biol., 2010 [Epub ahead of print].

[19] J. Sambrook, E.F. Fritsch, and T. Maniatis, Molecular Cloning: $A$ Laboratory Manual $2^{\text {nd }}$ ed. Cold Spring Harbor: Cold Spring Harbor Laboratory Press, vol. 3, appendix B.12, 1989.

[20] S. Sprio, A. Tampieri, G. Celotti, and E. Landi, "Development of hydroxyapatite/calcium silicate composites addressed to the design of load-bearing bone scaffolds", J. Mech. Behav. Biomed. Mater., vol. 2, pp. 147-155, 2009.

[21] H.Y. Juang, and M.H. Hon, "Effect of calcinations on sintering of hydroxyapatite", Biomaterials, vol. 17, pp. 2059-2064, 1996.

[22] C. Balçik, T. Tokdemir, A. Şenköylü, N. Koç, M. Timuçin, S. Akin, P. Korkusuz, and F. Korkusuz, "Early weight bearing of porous HA/TCP (60/40) ceramics in vivo: A longitudinal study in a segmental bone defect model of rabbit", Acta Biomaterialia, vol. 3, pp. 985-996, 2007.

[23] R.Z. Legeros, S. Lin, R. Rohanizadeh, D. Mijares, and J.P. Legeros, "Biphasic calcium phosphate bioceramics: preparation, properties and applications", J. Mater. Sci. Mater. Med., vol. 14, pp. 201-209, 2003.

[24] R.Z. Legeros, "Calcium Phosphate in Oral Biology and Medicine", Monograph Oral Sci., vol. 15, pp. 1-201, 1991.

[25] W.H. Song, Y.K. Jun, Y. Han, and S.H. Hong, "Biomimetic apatite coating on micro-arc oxidized titania", Biomater., vol. 25, pp. 3341-3349, 2004.

[26] T. Kokubo, and H. Takadama, "How useful is SBF in predicting in vivo bone bioactivity?", Biomater., vol. 27, pp. 2907-2915, 2006.

[27] Y. Gao, W. Weng, K. Cheng K, P. Du, G. Shen, G. Han, B. Guan and W. Yan, "Preparation, characterization and cytocompatibility of porous ACP/PLLA composites", J. Biomed. Mater. Res. A, vol. 79, pp. 193-200, 2006.

(C) Wongwitwichot et al.; Licensee Bentham Open.

This is an open access article licensed under the terms of the Creative Commons Attribution Non-Commercial License (http://creativecommons.org/ licenses/by-nc/3.0/) which permits unrestricted, non-commercial use, distribution and reproduction in any medium, provided the work is properly cited. 